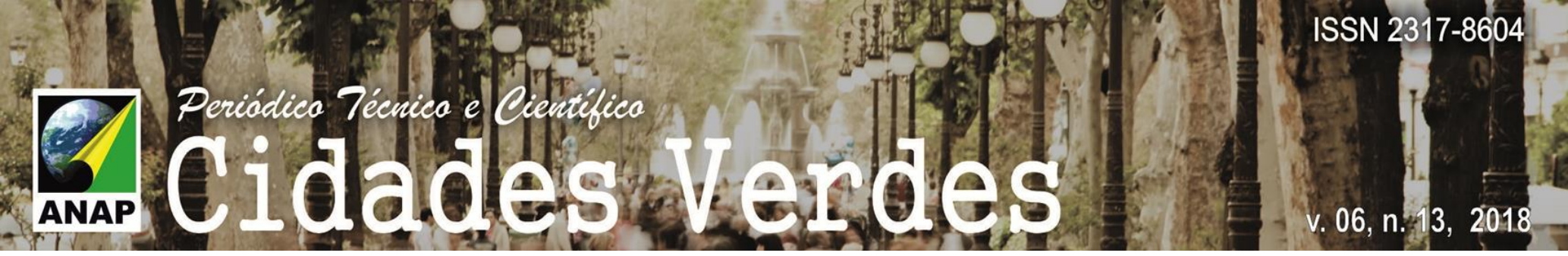

\title{
Resíduos Sólidos Municipais e os Catadores
}

Municipal Solid Waste and Waste Pickers

Residuos Sólidos Municipales y los Recolectores

Adriana Emi Büchler Otakara

Mestranda, Unoeste, Brasil emiotakara@gmail.com 


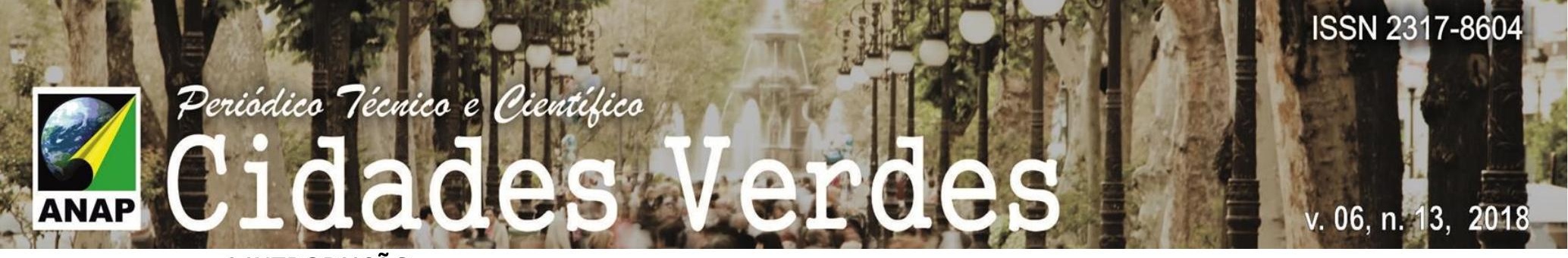

1 INTRODUÇÃO

A reciclagem veio como alternativa sustentável para a preservação do meio ambiente a fim de reduzir o volume de resíduos sólidos destinados aos lixões e aterros, aumentando sua vida útil, contribuindo com a limpeza urbana e auxiliando na preservação da exploração dos recursos naturais, uma vez que, conforme Medina (apud GALON e MARZIALE, 2016, p. 169) a “[...] intensificação dos padrões de consumo nas sociedades contemporâneas, que geram quantidades excessivas de resíduos sólidos urbanos", sendo fundamental o desenvolvimento da gestão adequada dos resíduos sólidos urbanos (RSU), pois um mau desenvolvimento desta atividades pode interferir na qualidade de vida da população.

O impacto dos resíduos sólidos na saúde coletiva e individual da população e ao meio ambiente advém principalmente pelas "deficiências no sistemas de coleta e disposição final e a ausência de uma política de proteção à saúde do trabalhador" (FERREIRA e ANJOS, 2001, p. 690) associado ao fato, conforme United Natios (apud FERREIRA e ANJOS, 2001, p. 690) relata, a dificuldade do controle da poluição ambiental acompanhar o ritmo do desenvolvimento, relação esta essencial para garantia da qualidade de vida, além de enfatizar a necessidade de verificar o padrão da cultura local para aplicação dos métodos.

Dentre a população mais afetada pelo RSU são os garis, catadores e trabalhadores de cooperativas de produtos recicláveis, com isso Galon e Marziale (2016, p. 173) fizeram uma revisão na literatura sobre as condições de trabalho e saúde destes trabalhadores na América Latina e identificaram que as pesquisas sobre o tema é recente e vem apresentando um aumento gradativo nos últimos vinte anos, sendo o Brasil o país que mais desenvolveu estudos na área, enquanto para Ferreira e Anjos (2001, p. 690) os resíduos sólidos municipais (RSM), saúde e o meio ambiente são pouco estudados em conjunto devido a uma relação de fatores, entre eles: pouco interesse pelo resíduo comum por parte dos profissionais, pesquisadores e população; pouca atenção dada pelo poder público e poucos profissionais com capacitação técnica. E para Porto (apud FERREIRA e ANJOS, 2001, p. 690) relata que a discussão entre questão ambiental e saúde coletiva ocorre no Brasil de forma paralela e sem articulação, o que deve ser mudado.

A inserção e reconhecimento da importância do papel dos catadores de materiais recicláveis são de grande valor, pois eles são elo importante nesta cadeira produtiva ao recuperarem e selecionarem os recursos descartados pela sociedade, auxiliando no processo de preservação do meio ambiente, desenvolvendo este papel mesmo que ainda suas ações são pouco valorizadas pela sociedade (GUTBERLET et al., 2016, p. 206).

Desta forma este trabalho faz uma revisão na literatura e identifica através dos estudos e pesquisas já realizados na área os principais riscos que estes trabalhadores estão expostos, as principais consequências em suas saúdes e as melhores formas de prevenção de acidentes. 


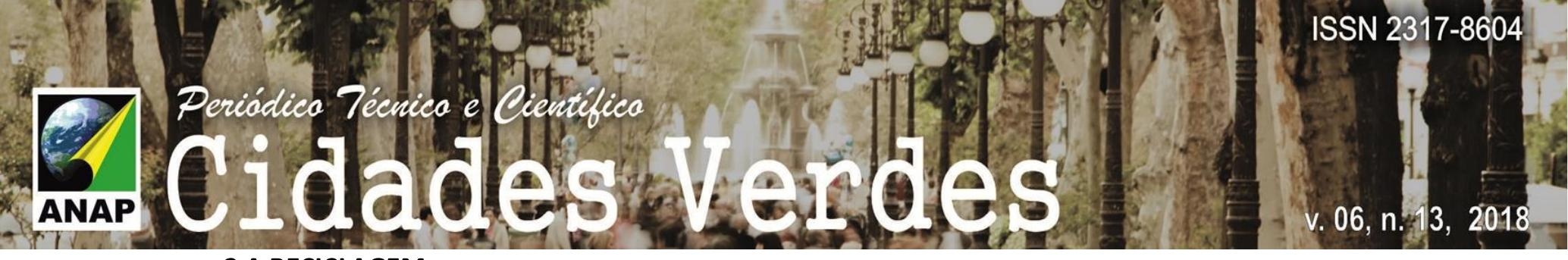

\section{A RECICLAGEM}

De acordo com Galon e Marziale (2016, p. 169) o Brasil apresenta características de um país em desenvolvimento, em que a reciclagem ainda não é estruturada, como no caso dos países desenvolvidos, e "[...] ainda se observa a destinação de resíduos aos lixões ou queima a céu aberto [...]", aumentando a fragilidade da população.

Um grande avanço no cenário nacional foi a implementação da Política Nacional de Resíduos Sólidos (PNRS), estabelecida pela Lei Federal no 12.305/2010, como diz seu Art. 1o:

Esta Lei institui a Política Nacional de Resíduo Sólido, dispondo sobre seus princípios, objetivos e instrumentos, bem como sobre as diretrizes relativas à gestão integrada e ao gerenciamento de resíduos sólidos, incluindo os perigos, às responsabilidades dos geradores e do poder público e aos instrumentos econômicos aplicáveis.

O estabelecimento da PNRS favoreceu o estímulo a reciclagem e a coleta seletiva dos resíduos urbanos, contribui assim para a melhoria da qualidade do meio ambiente e sua conservação e manutenção, além de auxiliar a consolidação das cooperativas de coleta seletiva na intenção de melhorar as condições de trabalho da população que depende economicamente da coleta de lixo, pois conforme Costa (apud FERREIRA et al., 2016, p. 153) este trabalhadores são de extrema pobreza, e segundo Medeiros e Macêdo (apud FERREIRA et al., 2016, p.153) no Brasil 500 mil são catadores de materiais recicláveis, sendo importante o auxílio do governo e população para melhorar as condições de trabalho deste segmento, principalmente por considerar que dentro deste setor de trabalhadores ligados de alguma forma com o RSM, com base em Buss e Pelegrini Filho (apud FERREIRA et al., 2016, p. 154), "[...] os determinantes sociais de saúde são fatores não biológicos que influenciam as condições de saúde de uma população".

Conforme levantamento realizado na literatura Galon e Marziale (2016, p. 170) identificaram que no Brasil, pelo elevado índice de desemprego e pobreza, parte do processo de reciclagem é realizado por catadores em muitos casos informais, com alto o índice de pessoas que dependem dessa atividade para sobrevivência, sendo sua atuação principalmente nas ruas, lixões, aterros sanitários, unidades de triagem ou cooperativas, em sua maioria em situações precárias e com grande risco de ocorrência de acidentes e/ou adoecimento.

\section{POTENCIAL POPULAÇÃO DE RISCO}

Os RSM podem gerar transtorno a população das áreas urbanas de diversas formas e com diferentes graus de intensidade, afetando uma grande parcela de forma indireta, através, por exemplo, da contaminação dos mananciais que abastecem a rede pública de água, e agindo diretamente em setores específicos da sociedade, que de algum modo têm contato direto com estes resíduos. 
Ferreira e Anjos (2001, p. 690-691) identificaram através da literatura existente sobre a relação saúde e RSM cinco grupos que apresentam maior potencial de vulnerabilidade, sendo eles: (1) populações que não possuem coleta domiciliar (em geram segmento pobre da sociedade) e que eliminam os resíduos próximos aos locais que residem - colocam em risco toda a população do entorno da área de descarte; (2) moradores vizinhos aos locais de tratamento ou depósito dos resíduos; (3) catadores nas áreas de descarte do resíduos sólido municipal, que ao remexerem no material depositado podem se contaminar com os mesmo, além do risco de acidentes. Esta população, que normalmente é vizinha das áreas de depósito, podem se tornar vetores de transmissão de doenças para parte da população que não vive nesta região; (4) população em geral, que pode ser contaminada pela poluição e contaminação dos corpos d'água e lençóis subterrâneos, consumo de carne de animais criados próximo as áreas de descarte dos RSM; (5) trabalhadores responsáveis pelo manuseio, transporte e destinação final dos resíduos.

\subsection{Características dos trabalhadores}

Na pesquisa realizada por Galon e Marziale (2016, p. 175) identificaram que os trabalhadores responsáveis pela coleta dos resíduos no geral apresentam baixa escolaridade, com presença de analfabetos e semianalfabetos, e que são pessoas que apresentam moradias precárias e em alguns casos identificaram presença de moradores de rua.

Os mesmos autores ainda apontam (2016, p. 176) que normalmente as pessoas passam a trabalhar como catadores por conta do desemprego, já que no geral possuem baixa escolaridade e pouca capacitação profissional em relação ao que o mercado atual exige, e encontram na atividade de coleta de resíduos a única possibilidade para geração de renda, sendo comum a presença de trabalhadores vindos da construção civil, agricultura, serviços gerais e trabalho doméstico. Porém, por ser uma atividade muitas vezes realizada por grupos familiares, foi identificada a presença de pessoas que iniciaram a atividade na infância e permaneceram nesta profissão na vida adulta.

\section{CONDIÇÕES DE TRABALHO}

No estudo realizado por Galon e Marziale (2016, p.176), verificou que a média da jornada de trabalho diária varia entre seis a oito horas, em média seis dias na semana, sendo comum trabalharem por longos períodos, pois normalmente a renda esta associada a horas de trabalho, portanto quanto mais se trabalhar, maior será o retorno financeiro, e os autores identificaram em alguns estudos de caso que, por ser uma atividade muitas vezes informal, é comum presença de pessoas que já possuem algum tipo de assistência do governo, como bolsa família, aposentados e pensionistas, sendo a atividade desenvolvida como um complemento da renda familiar.

Ferreira et al. (2016, p. 158-159) no estudo realizado entre os trabalhadores de uma cooperativa de catadores de materiais recicláveis em Ceilândia, no Distrito Federal, e identificaram que em média trabalham sete horas por dia, trabalhando 5,8 dias na semana, sendo que a maioria dos entrevistados na pesquisa alegaram trabalhar mais de seis anos como 
catadores, apresentando um elevado índice de continuidade da profissão. Nesta pesquisa os autores identificaram que a maioria das doenças relatadas estavam associadas as condições insalubres das atividades desenvolvidas.

No levantamento bibliográfico realizado por Galon e Marziale (2016 p. 177), identificaram nos estudos de caso de catadores de RSM três cenários de trabalho mais recorrentes: (1) lixões e aterros; (2) nas ruas; (3) em associações e cooperativas, com todos apresentando características semelhantes como contato direto com o resíduo, trabalho excessivo, baixa renda e falta de recursos, materiais e instrumentos adequados para realização das atividades, sendo este último um importante fator que pode levar a dano da saúde do operário.

Nos estudos analisados em lixões e aterros controlado, Galon e Marziale (2016 p. 177-178) apontaram que são locais de precária condição de trabalho, pois realizam a atividade em contato direto com as "montanhas de lixo" a céu aberto, exigindo grande esforço e expondose a grande risco, pois normalmente coletam o material com as próprias mãos ou com auxílio de instrumentos improvisados, geralmente caracterizado por ser uma atividade realizada em família. Estes locais dificilmente apresentam infraestrutura básica, como banheiros e refeitórios, sendo comum realizaram suas refeições em meio ao espaço do lixão ou aterro, não havendo interesse do governo público em providenciar estas instalações, por alegarem ser um incentivo a permanência da atividade no local, indo contra a política de incentivo a retirada da população dessas áreas. Um bom exemplo de eficiência na ação pública é citado por Colvero e Souza (2016, p. 2), na cidade de Anápolis, no estado de Goiás, que conseguiu criar uma cooperativa que centralizou a triagem dos catadores, que possibilitou a readequação do local de disposição final do resíduo sólido urbano (RSU) onde os catadores não possuem mais acesso.

Gutberlet et al. (2016, p. 206; 208) em sua pesquisa junto aos grupos de catadores da região metropolitana reforçam a falta de instalações adequadas para o trabalhadores, como banheiro, vestiários e refeitórios em condições de higiene e conforto, e destacam a ausência na maioria dos casos de acesso a água, ambientes com insuficiência de iluminação e ventilação e com excesso de umidade.

Galon e Marziale (2016, p. 178-180) e Gutberlet et al. (2016, p. 206) relatam que os catadores que atuam nas ruas normalmente utilizam para auxílio carros de mão e desenvolvem a atividade de forma individual e informal, sem horário definido, exposto ao risco por circular no trânsito das vias de veículos automotores, pois normalmente a população não os respeitam ao considerarem empecilhos no trânsito, riscos também ao manusear os materiais dos sacos e tambores de lixo e por carregar elevado peso de materiais. Normalmente desenvolvem suas atividades antes da passagem da coleta municipal, sendo poucos os que possuem clientes específicos, como lojas e supermercados, que possuem horário e dia específico para coleta.

No caso dos catadores que trabalham em associações e cooperativas, Galon e Marziale (2016, p.180-181), identificaram que são locais que apresentam melhores condições de trabalho por terem ajuda de organizações governamentais, não governamentais e/ou instituições que incentivam a sustentabilidade, garante assim benefícios e capacitação aos trabalhadores, auxiliando na consolidação social, porém, os autores identificaram que nos estudos de caso são poucos os ambientes que conseguem ter uma organização bem estruturada, que disponha de todos os equipamentos e estrutura necessários para o desenvolvimento adequados para as 
atividades, além da dificuldade dos municípios estabelecerem um sistema satisfatório de coleta dos resíduos, dificuldade de relacionamento entre os membros, levando a uma má gestão, falta de legislação que garanta proteção social e auxilie na inserção da valorização destes trabalhadores na sociedade.

\section{OS RISCOS E AS CONDIÇÕES DE SAÚDE DOS TRABALHADORES}

Os catadores dos RSM estão expostos a diversos riscos que variam seu grau de periculosidade de acordo com a atividade desenvolvida e da característica da área de trabalho.

No trabalho realizado por Colvero e Souza $(2016$, p. 5), ao estudarem os riscos presentes nos aterros controlados utilizando dois métodos diferentes, identificaram uma proximidade dos resultados que mostraram que os maiores riscos são os ergonômicos, psicossociais pelo excesso de horas de trabalho, ruído, perfurações e cortes, escorregamento, inalação de gases e fumos e atropelamento indicando a necessidade de intervenção/correção imediata.

Desta forma, através do levantamento da literatura foram selecionados os principais agentes de risco classificados dentro de quatro fatores: físicos, químicos, biológicos e ocupacionais.

\subsection{Agentes físicos}

Para Ferreira e Anjos (2001, p. 692) cinco principais agentes que causam riscos físicos identificados em seu trabalho, sendo eles: (1) odor pode ocasionar mar estar, cefaleias e náuseas; (2) ruído proporcionar a perda parcial ou total da audição, cefaleia, tensão nervosa, estresse, hipertensão arterial; (3) poeira pode acarretar em desconforto e perda momentânea da visão, além de problemas respiratórios e pulmonares; (4) vibração dos equipamentos pode provocar lombalgias, dores no corpo e estresse; (5) objetos perfurantes e cortantes podem acarretar em ferimentos.

Quanto aos materiais cortantes e perfurantes são responsáveis principalmente por ferimentos nos membros superiores e inferiores, como identificado no estudo de Lustosa et al. (2014, p. 93) por serem as áreas de maior contato com as sacolas de armazenamento.

Galon e Marziale (2016, p. 182) também identificaram que grande parte dos trabalhadores desenvolvem suas atividades expostos a altas temperaturas, muitas vezes ao sol intenso e chuva, em meio ao trânsito e com postura incorreta, este último, de acordo com o estudo realizado por Gutberlet et al. (2016, p. 207) "com frequência a separação é realizada com o material espalhado pelo chão, forçando os trabalhadores a permanecerem de cócoras, sentados em um pequeno banco ou mesmo em caixote improvisado como bancada de trabalho".

Ainda nos estudos de Gutberlet et al. (2016, p. 208) também identificaram que em suas pesquisas a ocorrência de acidentes no processo de prensagem, pois muitas vezes as máquinas não possuem proteção para as mãos, na etapa de pesagem, pois muitas balanças são antigas e exigem esforço físico por parte do trabalhador, podendo causar danos em sua coluna. 


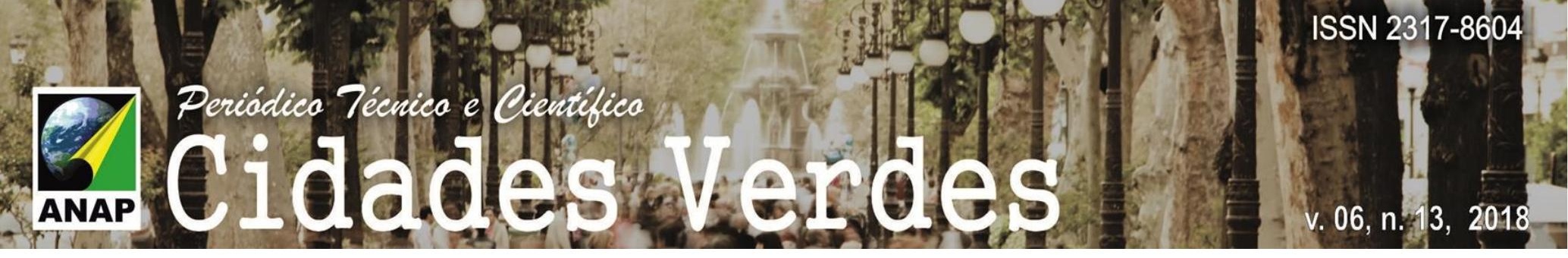

\subsection{Agentes químicos}

No processo de coleta dos RSM, os catadores são expostos, segundo Ferreira e Anjos (2001, p. 692) aos seguintes agentes químicos: (1) pilhas; (2) baterias; (3) óleos e graxos; (4) pesticidas/herbicidas; (5) solventes; (6) tintas; (7) produtos de limpeza; (8) cosméticos; (9) remédios; (10) aerossóis. Com o risco causado pelos metais pesados como chumbo podem provocar doenças com efeito cumulativo ou os pesticidas que podem gerar intoxicação aguda nos seres humanos (FERREIRA e ANJOS, 2001, p. 692). Além do risco pela intoxicação, Galon e Marziale (2016, p. 182-183) relatam que a presença de pilhas e aerossóis ao entrarem em contato com materiais inflamáveis possibilitam a ocorrência de incêndios.

\subsection{Agentes biológicos}

Os agentes biológicos podem causar doenças de forma direta e indireta. (FERREIRA e ANJOS, 2001, p. 692). A contaminação direta por micro-organismos patogênicos pode ocorrer através do contato de materiais oriundos da população, como "lenços de papel, curativos, fraldas descartáveis, papel higiênico, absorventes, agulhas e seringas descartáveis, camisinhas", mas a contaminação pode ocorrer também pelo contato dos resíduos gerados de "pequenas clínicas, farmácias, laboratórios", além do lixo hospitalar que não é corretamente descartado. A contaminação indireta ocorre quando a transmissão de doenças ocorre através de vetores que encontram nos resíduos um local propício para sobreviver e proliferar (FERREIRA e ANJOS, 2001, p. 692). Galon e Marziale (2016, p. 182) ainda complementam com a presença de animais mortos, como gatos, cachorros e ratos, fezes, urinas e em alguns casos presença de fetos humanos no lixo. Além dos animais mortos, Kirchner et al. $(2013$, p. 4) relata a presença de animais vivos que podem se tornarem vetores na transmissão de doenças para toda a população, como gatos, cães, ratos, baratas cobras e insetos, que se aproximam dos locais de armazenamento dos materiais em busca de alimentos.

Para Galon e Marziale (2016, p. 183) grande parte do risco do contato destes materiais pelos catadores é de responsabilidade da sociedade, por não realizarem a segregação adequada do material reciclável dos rejeitos orgânicos. Gutberlet et al. (2016, p. 207) também abordam o risco causado, principalmente para os catadores de porta a porta pelo condicionamento inadequado de materiais perfurantes e cortantes, e presença de materiais muito sujos, principalmente embalagens de alimentos que são descartadas sem prévia lavagem.

\subsection{Acidentes e riscos ocupacionais}

Os riscos de acidentes mais frequentes entre os trabalhadores que possuem contato direto com o RSM são: (1) cortes com vidros, que é o acidente mais comum, porém os acidentes são pouco notificados por na maioria das vezes serem considerados casos de pouca gravidade, na sua maioria os acidentes ocorrem pelo descarte incorreto da população associado à falta de uso dos equipamentos de proteção individual necessários para o manuseio com segurança dos materiais; (2) cortes e perfurações com outros objetos pontiagudos, ocorrendo normalmente 
com espinhos, pregos, agulhas de seringas e espetos, sua ocorrência apresenta as mesmas características do anterior; (3) queda de veículos, algumas vezes fatais, principalmente na coleta domiciliar por não disponibilizar de veículo adequado e pela alta taxa de alcoolismo entre os trabalhadores; (4) atropelamentos, principalmente entre os trabalhadores da coleta domiciliar e da limpeza dos logradouros, geralmente causados pela sobrecarga e velocidade do trabalho, falta de conscientização dos motoristas e falta de uniformes adequados; (5) outros motivos com maior frequência são a perda de membros nos equipamentos, mordidas e picadas de animais (FERREIRA e ANJOS, 2001, p. 693).

Para Galon e Marziale (2016, p. 182) os lixões e aterros apresentam grande risco de queda, soterramento e atropelamento, este último sendo classificado como grave pelo elevado índice de acidentes fatais pelos trabalhadores disputarem espaço com os caminhões e tratores. Nos estudos de Gutberlet et al. (2016, p. 207) a ocorrência da queda dos sacos contendo material para separação é alta, principalmente na recepção no processo de empilhamento.

Entre as doenças ocupacionais mais frequentes é a ocorrência de micose, pois as roupas usadas para trabalho contribuem para o desenvolvimento dos micro-organismos sendo comum ocorrência de micoses nos pés e mãos (GUTBERLET et al. 2016, p. 184) também pela falta de equipamentos de proteção individuais não adequados. Também são identificados índices elevados de doenças coronárias e de hipertensão arterial, além de doenças respiratórias, e contaminação de doenças como hepatite B e AIDS através de agulhas hipodérmicas, porém estes últimos dados não possuem estudos que comprovem sua relação dos trabalhadores com os RSM (FERREIRA e ANJOS, 2001, p. 694).

Alguns fatores fisiológicos também podem provocar problemas à saúde dos trabalhadores, como aos maus hábitos alimentares, tabagismo e alcoolismo, além de potencializar o risco de acidentes (FERREIRA e ANJOS, 2001, p. 694). No grupo estudado por Ferreira et al. (2016, p. 163), 6,6\% dos entrevistados apresentam problemas com o alcoolismo, e 34,6\% afirmavam serem fumantes. Essa associação é altamente prejudicial, pois o ambiente de trabalho associado aos hábitos de consumo de álcool e fumo naturalmente favorece o desenvolvimento de doenças respiratórias. Além do que, o consumo do álcool durante o horário de trabalho favorece a ocorrência de acidentes entre os trabalhadores (GALON E MARZIALE, 2016, p. 184), enquanto Dias (apud GUTBERLET et al., 2016, p. 209) relata também o consumo de drogas ilícitas por alguns trabalhadores como forma de expressar as dificuldades vivenciadas por esta profissão, enquanto Nicolau (apud GUTBERLET et al., 2016, p. 209) aborda a importância das associações e cooperativas para este grupo de trabalhadores, ao auxiliarem na sua inserção social como estimulo para parar o consumo de drogas.

De acordo com Fossa e Saad (apud GUTBERLET et al., 2016, p. 209), em relação ao álcool e os catadores de resíduo:

[...] o confronto da identidade do trabalhador com o valor atribuído à mesma, diante do mundo social, pode ser o gerador desse sofrimento. Os sentimentos de sofrimento surgem, também, da baixa autoestima que o trabalhador possui, sendo que a estratégia usada é a negação do próprio sofrimento e, em outros, é o uso excessivo de bebidas alcoólicas. 
Galon e Marziale (2016, p. 183) relatam que além de muitos catadores se contaminarem ao fazer refeições em locais inapropriados, muitos consomem produtos alimentos achados, principalmente produtos vencidos descartados pelas redes de supermercados. No estudo de Gutberlet et al. (2016, p. 207) identificam que também apresentam dificuldade para estabelecerem horário irregular para realizarem suas refeições, principalmente para os que trabalham na rua.

O estresse também aparece entre os sintomas entre os trabalhadores, normalmente associado a alta tensão e longas jornadas de trabalho, baixos salários e alto desgaste físico, podendo este fator ocasionar outros acidentes (FERREIRA e ANJOS, 2001, p. 694). Entre os desgastes psíquicos são identificados o "[...] desânimo, raiva, irritabilidade, ansiedade, baixa autoestima, desamparo e sentimento de humilhação [...]", possivelmente pela desvalorização e preconceito da profissão junto à sociedade ao serem tratados como marginais associados ao crime e a ilegalidade, não os enxergam como propulsores a melhoria da qualidade de vida através do auxílio para conservação do meio ambiente (GALON E MARZIALE, 2016, p. 185).

\subsection{Problemas de saúde}

No trabalho realizado por Ferreira et al. (2016, p. 159-163) identificaram que pouco mais da metade dos trabalhadores afirmaram que apresentavam alguma doença, sendo as mais citadas em ordem decrescente: hipertensão, alergias, dores de cabeça, hérnia de disco e lesão por esforço repetitivo (LER), entre outras, sendo que para a grande maioria dos entrevistados contam com o Sistema Único de Saúde (SUS) para o cuidado e tratamento, porém menos da metade dessas pessoas alegaram fazer consultas médicas periódicas para prevenção e/ou realização de tratamentos.

No levantamento dos estudos realizados por Galon e Marziale (2016, p. 184-185), identificaram que os problemas de saúde mais mencionados foram: "nervosismo, dores no corpo e articulações, cansaço, tosse, falta de ar, insônia, ardência nos olhos, coceira, enjoo, emagrecimento, dores abdominais, machas na pele [...] resfriados, conjuntivite, dengue, verminose, alergias e problemas dermatológicos. [...] asma, doenças sexualmente transmissíveis, hepatite, tuberculose e cólera", sendo o índice de DST com valores muito superiores a média nacional, possivelmente pelo risco exposto a contaminação biológica, o que exigiria um programa nacional para promoção da saúde. Nos estudos realizados por Kirchner et al. (2013, p. 4) além de alguns dos problemas já mencionados também a ocorrência de infecção intestinal (diarreia), gripe, leptospirose, meningite, dores de cabeça, febre e náuseas.

Ainda conforme Gutberlet et al. (2016, p. 184-185), o desenvolvimento de atividades com excesso de peso, com postura incorreta ou incômoda (inclinação constante para coleta do material), movimentos repetitivos junto às longas jornadas de trabalho também contribuem para dores musculoesqueléticas. Estes fatores associada à má alimentação contribuem para que nas pesquisas realizadas sobre a saúde dos catadores foi constatado que a anemia é uma doença constante neste grupo e pode tornar a atividade ainda mais incômoda e de difícil execução. No estudo realizado por Kirchner et al. $(2013$, p. 4) em uma associação de catadores 


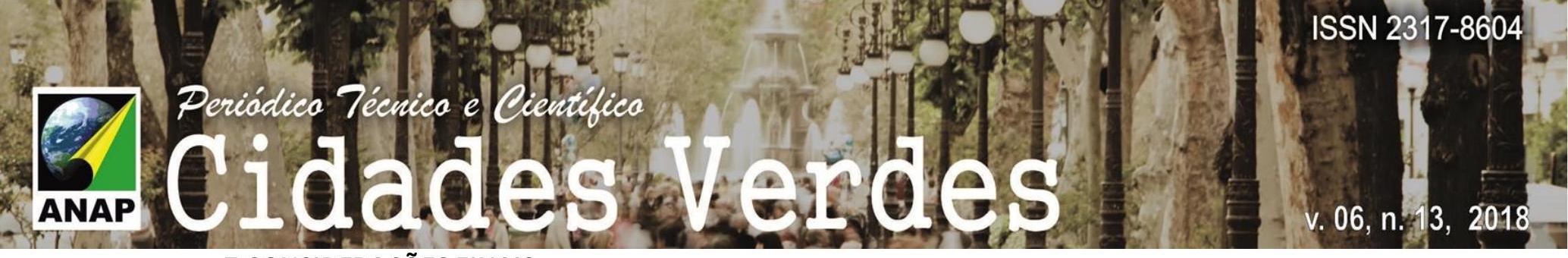

7 CONSIDERAÇõES FINAIS

Os RSM geram problemas ao meio ambiente e a saúde da população pela sua disposição inadequada que leva ao rompimento do equilíbrio do ecossistema (FERREIRA e ANJOS, 2001, p. 694), assim o incentivo a reciclagem se mostra como um mecanismo eficiente para o controle e manutenção do meio ambiente, de modo que os catadores de RSM passam a fazer um papel fundamental neste sistema, porém, estes trabalhados estão sujeitos a diversos riscos, pois como característica de país em desenvolvimento, não apresenta condições adequadas para estes trabalhadores desenvolverem suas atividades em segurança.

Verifica-se que grupos formados por cooperativas bem estruturadas e que possuem algum tipo de apoio por parte do governo municipal tendem a apresentar melhores condições de trabalho aos trabalhadores que apresentam menores riscos a saúde e uma melhora nas condições sociais, mesmo ainda apresentando certo grau de vulnerabilidade, sendo de grande importância o desenvolvimento de políticas públicas sociais e de saúde junto a estes grupos.

Boa parte dos acidentes são evitados através da ação da sociedade, ao fazerem a segregação correta entre os materiais recicláveis dos materiais orgânicos, e no caso de descarte de materiais cortantes, perfurantes e assemelhados fazer o condicionamento em embalagens apropriadas e devidamente identificados.

Também é fundamental a intervenção do poder público, desenvolvendo cursos de capacitação profissional, incentivando o uso dos equipamentos de proteção individual e desenvolvendo leis trabalhistas que garantam seus direitos e que auxiliem na inserção social.

Assim, percebe-se a importância de garantir as condições mínimas de segurança para os catadores através da infraestrutura adequada dos locais de trabalho, contendo espaços distintos da área de trabalho, sanitários e refeitórios, além de fornecerem os EPIs e estimularem seu uso e desenvolvendo ações de conscientização, como medida preventiva de acidentes, disponibilizar material de primeiros socorros para suporte na sua ocorrência garantindo que os catadores e desenvolver capacitação técnica dos trabalhadores a fim de garantir um ambiente de trabalho sem riscos a estes trabalhadores.

\section{AGRADECIMENTO}

Agradeço a Universidade do Oeste Paulista (Unoeste) e a CAPES que me auxiliam no desenvolvimento da pesquisa dentro do programa de Mestrado em Meio Ambiente e Desenvolvimento Regional.

\section{REFERÊNCIAS BIBLIOGRÁFICAS}

BRASIL. Presidência da República. Casa Civil. Lei Federal N 12.305, de 2 de agosto de 2010. Institui a Política Nacional de Resíduos Sólidos; altera a Lei $n^{\circ}$ 9.605, de 12 de fevereiro de 1998; e dá outras providências. Presidência da República. Casa Civil. Subchefia para Assuntos Jurídicos. Brasil, 2 ago. 2010. Disponível em: <http://www.planalto.gov.br/ccivil_03/_ato2007-2010/2010/lei//12305.htm>. Acesso em: 08 nov. 2016.

COLVERO, D. A.; SOUZA, S. M. Avaliação de riscos ocupacionais aos catadores de materiais recicláveis: estudo de caso no município de Anápolis, Goiás, Brasil. In: $7^{\circ}$ Fórum Internacional de Resíduo Sólido. 2016. Porto Alegre. Disponível em: http://firs.institutoventuri.com/images/7FIRS_Trabalho-Sibele_Maki.pdf. Acesso em: 30 out. 2016. 
